\title{
Fatigue of extruded AZ31B magnesium alloy under stress- and strain-controlled conditions including step loading
}

\author{
Fábio Castro ${ }^{\text {a }}$ Y Yanyao Jiang ${ }^{\text {b,* }}$ \\ ${ }^{a}$ Department of Mechanical Engineering, University of Brasilia, 70910-900 Brasilia, DF, \\ Brazil \\ ${ }^{\mathrm{b}}$ Department of Mechanical Engineering, University of Nevada, Reno, NV 89557, USA \\ Phone 775-784-4510, Fax 775-784-1701, E-Mail yjiang@unr.edu
}

* To whom correspondence should be addressed.

\begin{abstract}
Fatigue of extruded AZ31B magnesium alloy under stress- and strain-controlled loading conditions was investigated. The experimental program included uniaxial and axial-torsion tests conducted under constant amplitude loading and step loading. Observed fatigue lives and cracking orientations were used to evaluate two critical plane multiaxial fatigue criteria, namely, the Jiang criterion and the Fatemi-Socie criterion. The Jiang criterion is found to give satisfactory fatigue life predictions and a reasonable description of the cracking behavior. The Fatemi-Socie criterion provides a similar performance for most of the loading cases. For some of the uniaxial stress-controlled experiments, the fatigue life and early cracking predictions by the Fatemi-Socie criterion do not agree well with the experimental results. A discussion on the implications of stress-controlled loading conditions to fatigue modeling is presented.
\end{abstract}

Keywords: Magnesium alloy; Multiaxial fatigue; Ratcheting; Critical plane approach; Fatigue life; Step loading

\section{Introduction}

Lightweighting vehicles is an effective approach to reduce fuel consumption and greenhouse gas emissions (Pollock, 2010; Rowe, 2012). Among the materials being used and developed for lightweight designs, magnesium $(\mathrm{Mg})$ alloys play a key role due to their ultralightweight and high specific strength. Although the current use of $\mathrm{Mg}$ alloys is mainly in non-structural casting parts, wrought $\mathrm{Mg}$ alloys are increasingly being considered in structural applications (Agnew, 2004; Bettles and Barnett, 2012; Bettles and Gibson, 2005; Gaines et al., 1996). Since most load-bearing members in vehicles are subjected to cyclic loading, the avoidance of fatigue failure is a major design consideration. An understanding of the cyclic deformation and fatigue of $\mathrm{Mg}$ alloys is required before they can be reliably applied in critical structural components. 
Extensive strain-controlled uniaxial fatigue experiments have been conducted on $\mathrm{Mg}$ alloys (see (Begum et al., 2009; Chen et al., 2015,2007; Hasegawa et al., 2007; Jordon et al., 2013; Li et al., 2010; Lv et al., 2011,2009; Park et al., 2010; Sajuri et al., 2008; Wu et al., 2016,2010; Xiong et al., 2016; Xiong and Jiang, 2014; Yu et al., 2012) and references therein). Strain amplitude, strain ratio, loading rate, and material anisotropy are among the influencing factors investigated. Efforts have also been made to understand the fatigue cracking mechanisms in Mg alloys (Wang et al., 2014; Wen et al., 2016; Yu et al., 2011a). Fatigue and ratcheting deformation of $\mathrm{Mg}$ alloys under asymmetric stress-controlled loading have also been studied (Chen et al., 2015; Dallmeier et al., 2015; Kang et al., 2014; Lin et al., 2013a,2013b,2013c; Xiong et al., 2014; Xiong and Jiang, 2014; Zhang et al., 2011), although to a less extent. Most of the experiments conducted so far employed constant amplitude uniaxial loading. Multi-step loading has been investigated in very few studies (Lin et al., 2013c; Zhang et al., 2011).

Investigations on multiaxial fatigue of $\mathrm{Mg}$ alloys have been limited to a few types of $\mathrm{Mg}$ alloys, stress states, and loading histories (Albinmousa et al., 2011; Albinmousa and Jahed, 2014; Bentachfine et al., 1996; Xiong et al., 2012; Yu et al., 2011). The studied Mg alloys include extruded magnesium-lithium, AZ61A, and AZ31B, with experiments being conducted under constant-amplitude strain-controlled axial-torsion loading using tubular specimens. It was found that some of the existing fatigue criteria, namely, the Fatemi-Socie criterion (Fatemi and Socie, 1988), the Jiang-Sehitoglu criterion (Jiang and Sehitoglu, 1992), the Jiang criterion (Jiang, 2000), and the Jahed-Varvani criterion (Jahed and Varvani, 2006), can provide reasonable fatigue life predictions for the investigated materials and loading paths. Very limited work ( $\mathrm{Li}$ et al., 2016) has been conducted on cyclic deformation and fatigue of $\mathrm{Mg}$ alloys under multiaxial stress-controlled loading.

A recent study (Castro and Jiang, 2016) concluded that the Jiang criterion can reasonably predict the fatigue life and early cracking orientation of an extruded AZ31B Mg alloy. The fatigue experiments were conducted under constant amplitude strain-controlled loading and fully reversed shear strain with a superimposed static axial stress. Although the results obtained are satisfactory, materials in real structural members are generally subjected to complex loading which may involve, for example, mean loads, varying amplitude, loading mode alternation, and overloads. In addition, materials in engineering components can be loaded under a condition other than stress-control or strain-control mode. Therefore, it is desirable to evaluate the existing fatigue models using more complicated loading histories.

In the current work, the Jiang criterion is further evaluated based on the experimentally observed cracking behavior and fatigue life of an extruded AZ31B Mg alloy. The fatigue experiments were conducted under uniaxial and axial-torsion loading histories. Constant amplitude loading and step loading experiments under both stress- and strain-controlled conditions were examined. Predictions based on the Fatemi-Socie criterion are also obtained for comparative purposes. A discussion on fatigue modeling of materials under stresscontrolled conditions is presented.

\section{Material and experiments}


Extruded AZ31B Mg alloy was used in the current investigation. The chemical composition of the material in weight percentage is $2.5-3.5 \mathrm{Al}, 0.7-1.3 \mathrm{Zn}, 0.2 \mathrm{Mn}, 0.3 \mathrm{Si}$, $0.05 \mathrm{Cu}, 0.005 \mathrm{Ni}, 0.005 \mathrm{Fe}$, and $\mathrm{Mg}$ as balance. The grain structure of the material consists of elongated grains along the extrusion direction with widths ranging from 2 to $15 \mu \mathrm{m}$ and equiaxed grains on the plane normal to the extrusion direction with an average size of $90 \mu \mathrm{m}$. No twins were detected in the untested material. The Young's modulus of the material is $44.8 \mathrm{GPa}$, the $0.2 \%$ offset yield stress in tension is $244 \mathrm{MPa}$, and the ultimate strength under tension is $298 \mathrm{MPa}$. Detailed static mechanical properties of the AZ31B Mg alloy can be found in earlier publications (Castro and Jiang, 2016 ; Xiong et al., 2012).

All experiments were conducted at room temperature using an Instron axial-torsion servohydraulic load frame. The testing system has a capacity of $\pm 222 \mathrm{kN}$ in axial force and $\pm 2800 \mathrm{Nm}$ in torque, and is equipped with the Instron 8800 digital controller. Three loading conditions were investigated, namely, uniaxial stress-controlled, axial-torsion stresscontrolled, and axial-torsion strain-controlled. The stress-controlled uniaxial experiments were performed on solid cylindrical specimens with a gage length of $15 \mathrm{~mm}$ and a diameter of $10 \mathrm{~mm}$. A clip-on extensometer with gage length of $12.7 \mathrm{~mm}$ and a range of $\pm 10 \%$ was employed to measure the axial strain. The axial-torsion experiments were conducted on thinwalled tubular specimens with a gage section of $30 \mathrm{~mm}$, inner diameter of $20 \mathrm{~mm}$, and wall thickness of $2 \mathrm{~mm}$. In these experiments, a modified MTS extensometer capable of measuring axial, shear, and diametral strains was used. The extensometer has a range of $\pm 5 \%$ in the axial strain and of $\pm 3 \%$ in the shear strain. All specimens were cut from extruded round bars with their axes parallel to the extrusion direction. The gage section of each specimen was successively polished with silicon carbide papers with grit numbers ranging from 400 to 1200 in order to remove machining marks. 
(a)
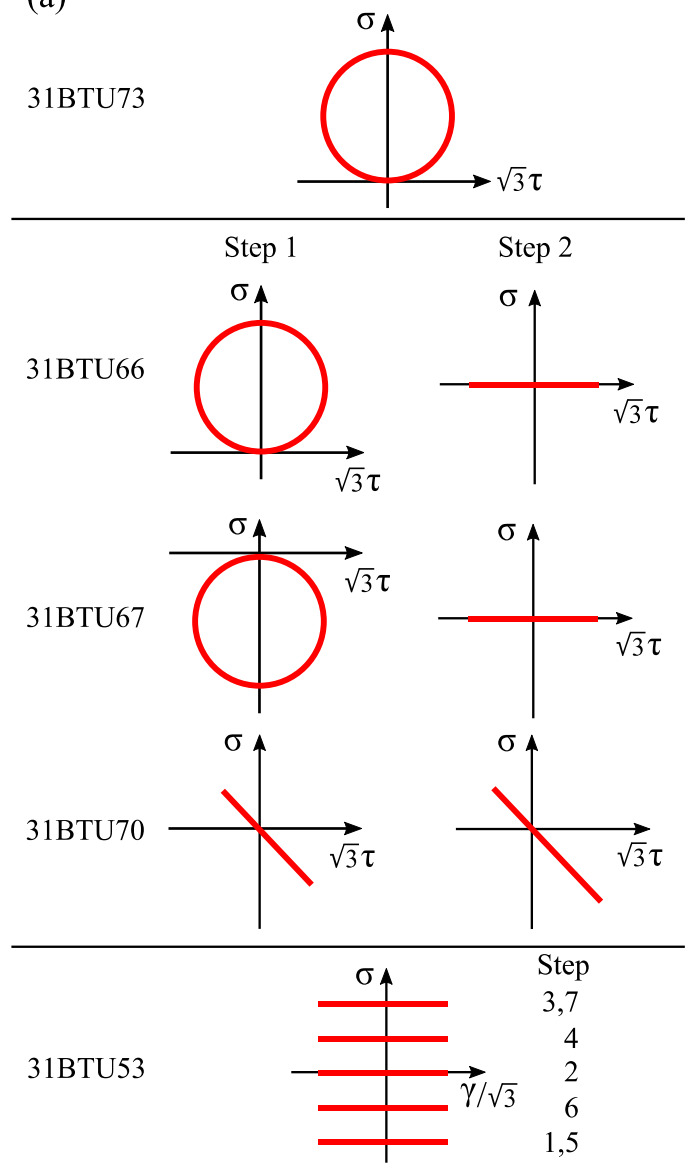

(b)

31BTU58 31BTU59

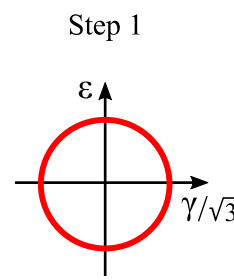

Step 2

$31 \mathrm{BTU} 62$ 31BTU63
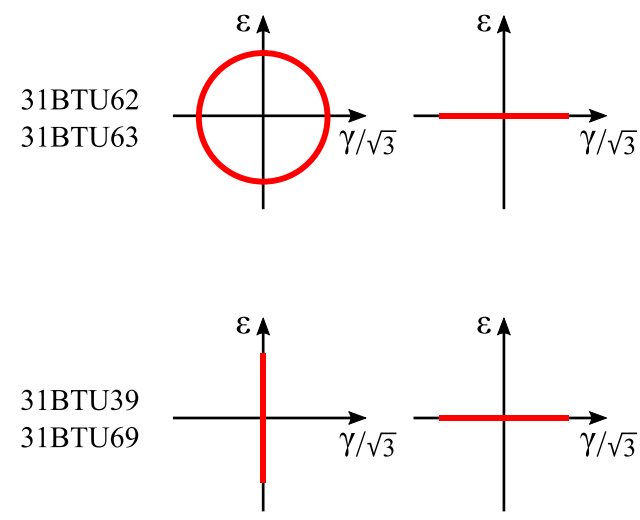

31BTU68

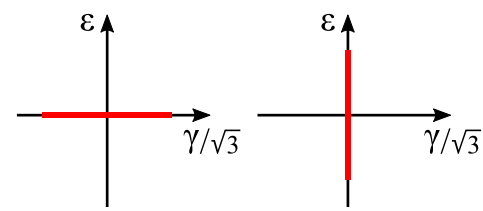

Figure 1. Stress-controlled (a) and strain-controlled (b) axial-torsion loading paths.

The uniaxial stress-controlled experiments include one-step, two-step, and multi-step loading. The multiaxial experiments were conducted under stress- and strain-controlled conditions with the loading paths shown in Fig. 1. The stress-controlled loading paths include $90^{\circ}$ out-of-phase loading, two-step $90^{\circ}$ out-of-phase and torsion loading, two-step proportional-proportional loading, and fully reversed shear strain with multiple superimposed static axial stresses. The strain-controlled experiments include two-step loading sequences of the following types: $90^{\circ}$ out-of-phase axial-torsion followed by tensioncompression, $90^{\circ}$ out-of-phase axial-torsion followed by torsion, tension-compression followed by torsion, and torsion followed by tension-compression.

Table 1. Stress-controlled uniaxial experiments on extruded AZ31B.

\begin{tabular}{cccrrrrr}
\hline $\begin{array}{c}\text { Specimen } \\
\text { ID }\end{array}$ & Load type & $\begin{array}{c}\mathrm{f} \\
(\mathrm{Hz})\end{array}$ & $\begin{array}{c}\Delta \mathrm{P} / 2 \\
(\mathrm{kN})\end{array}$ & $\begin{array}{c}\mathrm{P}_{\mathrm{m}} \\
(\mathrm{kN})\end{array}$ & $\begin{array}{c}\Delta \sigma / 2 \\
(\mathrm{MPa})\end{array}$ & $\begin{array}{c}\sigma_{\mathrm{m}} \\
(\mathrm{MPa})\end{array}$ & $\begin{array}{c}N_{i} \\
(\text { cycles })\end{array}$ \\
\hline 31BUN04 & One-step & 1 & 9.2 & 9.2 & 125 & 125 & 3,120 \\
31BUN07 & One-step & 1 & 13.6 & 0 & 175 & 0 & 760 \\
31BUN09 & One-step & 0.5 & 12.5 & 0 & 160 & 0 & 2,820 \\
31BUN12 & One-step & $0.5 / 1$ & 13.5 & 5.8 & 175 & 75 & 2,420 \\
31BUN13 & One-step & 1 & 14.4 & 6.6 & 185 & 85 & 1,180 \\
31BUN21 & One-step & 2 & 5.4 & 5.4 & 125 & 126 & 2,800 \\
31BUN22 & One-step & $2 / 5$ & 4.8 & 4.8 & 111 & 111 & 12,200 \\
31BUN23 & One-step & 2 & 4.8 & 0.4 & 112 & 122 & 6,520
\end{tabular}




\begin{tabular}{rccrrrrr} 
31BUN24 & One-step & $1 / 2$ & 5.6 & -1.1 & 129 & -24 & 31,300 \\
31BUN25 & One-step & $1 / 2 / 4$ & 5.6 & 4.3 & 132 & 101 & 4,620 \\
31BUN26 & One-step & 1.5 & 5.0 & 5.0 & 116 & 117 & 6,660 \\
31BUN27 & One-step & $1 / 5$ & 5.6 & 3.9 & 131 & 91 & 7,700 \\
31BUN05 & Two-step & $0.2 / 1$ & 9.7 & -9.7 & 125 & -125 & 29,300 \\
& & 1 & 9.7 & 9.7 & 125 & 125 & 3,160 \\
31BUN06 & Two-step & $0.2 / 1$ & 11.7 & -11.7 & 150 & -150 & 7,140 \\
& & 1 & 17.5 & -5.8 & 225 & -75 & 2,200 \\
31BUN08 & Two-step & $0.5 / 1$ & 13.5 & -5.8 & 175 & -75 & 3,940 \\
& & 0.5 & 13.5 & -7.7 & 175 & 75 & 1,580 \\
31BUN03 & \multirow{2}{*}{ Multi-step } & $0.25 / 2$ & 7.7 & -7.7 & 100 & -100 & 9,200 \\
& & 1 & 9.7 & -9.7 & 125 & -125 & 8,100 \\
& & 1 & 11.6 & -11.6 & 150 & -150 & 5,000 \\
& & 2 & 7.7 & -7.7 & 100 & -100 & 26,600 \\
& & 1 & 11.6 & -11.6 & 150 & -150 & 3,000 \\
& & 1 & 15.4 & -7.7 & 200 & -100 & 3,600 \\
& & 0.5 & 17.4 & -5.8 & 225 & -75 & 1,220 \\
& & 0.5 & 19.3 & -3.9 & 250 & -50 & 20 \\
\hline
\end{tabular}

$\mathrm{f}=$ frequency; $\Delta \mathrm{P} / 2=$ load amplitude; $\mathrm{P}_{\mathrm{m}}=$ mean load; $\Delta \sigma / 2=$ axial stress range; $\sigma_{\mathrm{m}}=$ mean axial stress; $N_{i}=$ number of cycles applied at the $i$ th loading level.

Table 2. Stress-controlled axial-torsion experiments on extruded AZ31B.

\begin{tabular}{|c|c|c|c|c|c|c|c|c|c|c|c|}
\hline $\begin{array}{l}\text { Specimen } \\
\text { ID }\end{array}$ & Load type & $\begin{array}{c}\mathrm{f} \\
(\mathrm{Hz})\end{array}$ & $\begin{array}{l}\Delta \mathrm{P} / 2 \\
(\mathrm{kN})\end{array}$ & $\begin{array}{l}\Delta \mathrm{T} / 2 \\
(\mathrm{Nm})\end{array}$ & $\begin{array}{c}\Delta \sigma / 2 \\
(\mathrm{MPa})\end{array}$ & $\begin{array}{c}\Delta \tau / 2 \\
(\mathrm{MPa})\end{array}$ & $\begin{array}{c}\varepsilon_{\mathrm{m}} \\
(\%)\end{array}$ & $\begin{array}{l}\Delta \varepsilon / 2 \\
(\%)\end{array}$ & $\begin{array}{l}\gamma_{\mathrm{m}} \\
(\%)\end{array}$ & $\begin{array}{c}\Delta \gamma / 2 \\
(\%)\end{array}$ & $\begin{array}{c}N_{i} \\
\text { (cycles) }\end{array}$ \\
\hline 31BTU73 & $90 \mathrm{OP}$ & 0.5 & 15.4 & 90.5 & 112.5 & 65 & 1.28 & 1.28 & 0.37 & 0.61 & 1,020 \\
\hline \multirow[t]{2}{*}{ 31BTU66 } & Two-step & 0.5 & 17.3 & 101.2 & & & 3.37 & 0.35 & 0.61 & 0.71 & 140 \\
\hline & (90OP-TO) & 0.5 & & 120.0 & & & 3.91 & 0.01 & 0.70 & 0.96 & 1,260 \\
\hline \multirow[t]{2}{*}{ 31BTU67 } & Two-step & 0.5 & 10.5 & 60.7 & 75 & 43.3 & -2.60 & 0.21 & -0.05 & 0.30 & 300 \\
\hline & (90OP-TO) & 0.5 & & 120.0 & & & -2.16 & 0.01 & -0.03 & 1.10 & 2,680 \\
\hline \multirow[t]{2}{*}{ 31BTU70 } & Two-step & 0.5 & 10.3 & 60.0 & & & & & 0.30 & 0.29 & 3,800 \\
\hline & (PP-PP) & 0.5 & 12.3 & 72.3 & & & & & 1.59 & 0.42 & 15,140 \\
\hline $\begin{array}{l}\text { Specimen } \\
\text { ID }\end{array}$ & Load type & $\begin{array}{c}\mathrm{f} \\
(\mathrm{Hz})\end{array}$ & \multicolumn{2}{|c|}{$\begin{array}{l}\mathrm{P}_{\text {stat }} \\
(\mathrm{kN})\end{array}$} & \multicolumn{3}{|c|}{$\begin{array}{c}\sigma_{\text {stat }} \\
(\mathrm{MPa})\end{array}$} & \multicolumn{3}{|c|}{$\begin{array}{l}\Delta \gamma / 2 \\
(\%)\end{array}$} & $\begin{array}{c}N_{i} \\
\text { (cycles) }\end{array}$ \\
\hline \multirow[t]{6}{*}{ 31BTU53 } & Multi-Step & 1 & \multicolumn{2}{|c|}{-16.3} & \multicolumn{3}{|c|}{-120} & \multicolumn{3}{|c|}{0.52} & 40 \\
\hline & (NPP) & 1 & \multirow{2}{*}{\multicolumn{2}{|c|}{$\begin{array}{c}0 \\
16.3\end{array}$}} & \multirow{2}{*}{\multicolumn{3}{|c|}{$\begin{array}{c}0 \\
120\end{array}$}} & \multicolumn{3}{|c|}{0.52} & 7,640 \\
\hline & & 1 & & & \multirow{2}{*}{\multicolumn{3}{|c|}{20}} & \multicolumn{3}{|c|}{0.52} & 440 \\
\hline & & 1 & \multicolumn{2}{|c|}{2.7} & & & & \multicolumn{3}{|c|}{0.52} & 7,300 \\
\hline & & 1 & \multicolumn{2}{|c|}{-16.3} & \multicolumn{3}{|c|}{-120} & \multirow{2}{*}{\multicolumn{3}{|c|}{$\begin{array}{l}0.52 \\
0.52\end{array}$}} & 3,680 \\
\hline & & 1 & \multicolumn{2}{|c|}{-2.7} & \multicolumn{3}{|c|}{-20} & & & & 440 \\
\hline
\end{tabular}


$\mathrm{f}=$ frequency $\Delta \mathrm{P} / 2=$ axial force amplitude $\Delta \mathrm{T} / 2=$ torque amplitude; $\Delta \sigma / 2=$ axial stress amplitude $\Delta \tau / 2=$ shear stress amplitude; $\varepsilon_{\mathrm{m}}=$ mean axial strain; $\Delta \varepsilon / 2=$ axial strain amplitude; $\gamma_{\mathrm{m}}=$ mean shear strain; $\Delta \gamma / 2=$ shear strain amplitude; $N_{i}=$ number of cycles applied at the $i$ th loading level.

Table 3. Strain-controlled axial-torsion experiments on extruded AZ31B.

\begin{tabular}{|c|c|c|c|c|c|c|c|c|c|}
\hline $\begin{array}{l}\text { Specimen } \\
\text { ID }\end{array}$ & Load type & $\begin{array}{c}\mathrm{f} \\
(\mathrm{Hz})\end{array}$ & $\begin{array}{c}\Delta \varepsilon / 2 \\
(\%)\end{array}$ & $\begin{array}{l}\Delta \gamma / 2 \\
(\%)\end{array}$ & $\begin{array}{c}\Delta \sigma / 2 \\
(\mathrm{MPa})\end{array}$ & $\begin{array}{c}\sigma_{\mathrm{m}} \\
(\mathrm{MPa})\end{array}$ & $\begin{array}{c}\Delta \tau / 2 \\
(\mathrm{MPa})\end{array}$ & $\begin{array}{c}\tau_{\mathrm{m}} \\
(\mathrm{MPa})\end{array}$ & $\begin{array}{c}N_{i} \\
\text { (cycles) }\end{array}$ \\
\hline \multirow[t]{2}{*}{ 31BTU58 } & 900P-TC & 0.1 & 1 & 1.732 & & & & & 26 \\
\hline & & 0.2 & 1 & 0 & 236 & 47.1 & & & 230 \\
\hline \multirow[t]{2}{*}{ 31BTU59 } & 900P-TC & 0.1 & 1 & 1.732 & & & & & 20 \\
\hline & & 0.5 & 0.5 & 0 & 170 & 5.9 & & & 1,952 \\
\hline \multirow[t]{2}{*}{ 31BTU62 } & 900Р-TO & 0.1 & 1 & 1.732 & & & & & 20 \\
\hline & & 0.2 & 0 & 1.732 & & & 119.0 & -1.3 & 100 \\
\hline \multirow[t]{2}{*}{ 31BTU63 } & 900Р-TO & 0.1 & 1 & 1.732 & & & & & 20 \\
\hline & & 0.8 & 0 & 0.866 & & & 93.0 & 0.1 & 3,594 \\
\hline \multirow[t]{2}{*}{ 31BTU39 } & TC-TO & 0.2 & 1 & & & & & & 10 \\
\hline & & 1.5 & & 0.52 & & & 65.2 & 0.5 & 30,707 \\
\hline \multirow[t]{2}{*}{ 31BTU69 } & TC-TO & 0.2 & 1 & & & & & & 20 \\
\hline & & 0.8 & & 0.866 & & & 79.3 & -0.1 & 2,922 \\
\hline \multirow[t]{2}{*}{ 31BTU68 } & TO-TC & 0.2 & & 1.732 & & & & & 20 \\
\hline & & 0.5 & 0.5 & & 187.2 & 33.1 & & & 2,082 \\
\hline
\end{tabular}

Results from the fatigue experiments are summarized in Tables 1-3. True stresses and strains are reported. The cross-section dimensions of the specimen during an experiment were determined by considering the elastic deformation and plastic incompressibility of the material. For the tubular specimens, averaged axial and shear stresses were calculated from the measured loads by assuming uniform axial and shear stress distributions over the wall thickness. The shear strain at the outer surface of the tubular specimen is used in the current study. The stress/strain quantities listed in Tables 1-3 were taken from a stress-strain hysteresis loop corresponding approximately to half of the number of cycles applied at the $i$ th loading level. The uniaxial specimens were tested until fracture into two parts or the appearance of a visible surface crack. For the tubular specimens, the experiments were conducted until the moment when the maximum stress in a loading cycle dropped below 5\% of the stabilized or peak value, or a visible crack was found on the outer surface of the specimen.

\section{Fatigue models}

Critical plane approaches are generally considered the most appropriate for an engineering description of fatigue damage (Jiang et al., 2007; Socie and Bannantine, 1988). Such approaches recognize that fatigue cracking occurs on specific material planes and that cracking behavior is material, stress state, and loading magnitude dependent. In critical plane 
models, fatigue failure is predicted when the fatigue damage accumulation on a material plane reaches a limit. Different physical quantities have been proposed to evaluate the fatigue damage on a material plane. In the last few decades, experimental evaluations (Fatemi and Shamsaei, 2011; Gao et al., 2009; Jiang et al., 2007; Kalnaus and Jiang, 2008; Kim et al., 2000,1999; Socie, 1993; Socie and Bannantine, 1988; Zhao and Jiang, 2008) have demonstrated the capability of critical plane models to predict crack initiation in a variety of engineering metallic materials and loading conditions.

Two critical plane approaches, namely, the Jiang criterion (Jiang, 2000) and the Fatemi-Socie criterion (Fatemi and Socie, 1988), are evaluated in the current study. Recent investigations (Castro and Jiang, 2016; Xiong et al., 2012) have found that these two criteria can provide reasonable fatigue life and cracking orientations for extruded AZ31B Mg alloy. Loading conditions investigated included strain-controlled axial-torsion loading and fully reversed torsion with superimposed static axial stress. The current study is an effort to further evaluate these two criteria using the fatigue experiments presented in the previous section.

\subsection{Jiang criterion}

Jiang (2000) developed a critical plane multiaxial fatigue criterion that combines the concepts of plastic strain energy density and material memory. The criterion is expressed in the following incremental form,

$$
\mathrm{d} D=\left\langle\frac{\sigma_{\mathrm{mr}}}{\sigma_{0}}-1\right\rangle^{m}\left(1+\frac{\sigma}{\sigma_{\mathrm{f}}}\right) \mathrm{d} Y
$$

where

$$
\mathrm{d} Y=b \sigma \mathrm{d} \varepsilon^{\mathrm{p}}+\frac{1-b}{2} \tau \mathrm{d} \gamma^{\mathrm{p}}
$$

In the above expressions, $D$ represents the fatigue damage, $Y$ is the plastic strain energy density on a material plane, and the prefix $d$ denotes an increment. $\sigma$ is the normal stress and $\tau$ is the shear stress on a material plane. The quantities $\varepsilon^{\mathrm{p}}$ and $\gamma^{\mathrm{p}}$ represent plastic strains corresponding to $\sigma$ and $\tau$, respectively. $\sigma_{\mathrm{mr}}$ is a material memory parameter. $\sigma_{0}$ and $\sigma_{\mathrm{f}}$ are the endurance limit and the true fracture stress of the material, respectively. The symbols $b$ and $m$ are material constants. The MacCauley brackets \langle\rangle are used to ensure that when $\sigma_{\mathrm{mr}} \leq \sigma_{0}$ the fatigue damage is minimal. The critical plane is defined as the material plane where the fatigue damage accumulation first reaches a critical value, $D_{0}$.

The Jiang criterion is applicable for general multiaxial loading. For any loading history, fatigue damage can be determined incrementally using Eq. (1). In the cases where a loading cycle can be identified, it is convenient to calculate the fatigue damage per loading cycle,

$$
\Delta D=\left\langle\frac{\sigma_{\mathrm{mr}}}{\sigma_{0}}-1\right\rangle^{m} \oint\left(1+\frac{\sigma}{\sigma_{\mathrm{f}}}\right)\left(b \sigma \mathrm{d} \varepsilon^{\mathrm{p}}+\frac{1-b}{2} \tau \mathrm{d} \gamma^{\mathrm{p}}\right)
$$


where the integration is taken over a loading cycle. The memory parameter $\sigma_{\mathrm{mr}}$ in Eq. (3) is the maximum von Mises equivalent stress in a loading cycle. The fatigue damage accumulated after $N$ loading cycles is the sum of the damage caused by each loading cycle,

$$
D=\sum_{j=1}^{N} \Delta D
$$

Fatigue failure is predicted to occur when the accumulated fatigue damage on a material plane first reaches a critical value $D_{0}$,

$$
D=\sum_{j=1}^{N_{\text {pred }}} \Delta D=D_{0}
$$

where $N_{\text {pred }}$ is the predicted fatigue life. Equations (3)-(5) can take account of materials that exhibit considerable transient behavior and/or are subjected to any loading history described in cycle-by-cycle basis.

For constant amplitude loading when the stabilized stress-strain response is reached well before half the total number of loading cycles to failure, Eq. (5) can be simplified to

$$
N_{\text {pred }}=\frac{D_{0}}{\Delta D_{a}}
$$

where $\Delta D_{a}$ is the fatigue damage per loading cycle of the stabilized loading cycle. A detailed description of the Jiang criterion including the procedure to determine the material constants can found in (Jiang, 2000).

\subsection{Fatemi-Socie criterion}

Fatemi and Socie (1988) developed a fatigue parameter for materials that exhibit shear cracking behavior,

$$
\mathrm{FP}=\frac{\Delta \gamma}{2}\left(1+K \frac{\sigma_{\mathrm{n} \max }}{\sigma_{\mathrm{y}}}\right)
$$

where $\Delta \gamma / 2$ is the shear strain amplitude and $\sigma_{\text {nmax }}$ is the maximum normal stress in a loading cycle on a material plane. $\sigma_{\mathrm{y}}$ is the yield strength of the material and $K$ is a material constant. The following format for the fatigue damage per loading cycle is used,

$$
\Delta D=\frac{\left\langle\mathrm{FP}-\mathrm{FP}_{0}\right\rangle^{\xi}}{C}
$$

where $\mathrm{FP}_{0}, \xi$, and $C$ are material constants which are obtained by best fitting experimental data from constant amplitude experiments. The MacCauley brackets \langle\rangle are used to ensure that when the fatigue parameter $\mathrm{FP}$ is less than the threshold value $\mathrm{FP}_{0}$, fatigue damage is minimal. 
Fatigue damage accumulation based on the Palmgren-Miner rule (Miner, 1945; Palmgren, 1924) is employed due to its ease of use. Therefore, fatigue failure is predicted to occur when the cumulative fatigue damage on a material plane reaches unity,

$$
\sum_{j=1}^{N_{\text {pred }}} \Delta D=1
$$

where $N_{\text {pred }}$ is the predicted fatigue life. For constant amplitude loading when the transient cyclic behavior is short-lived as compared with the total number of cycles to failure, Eqs. (8) and (9) are equivalent to the following fatigue curve expression,

$$
\left\langle\mathrm{FP}-\mathrm{FP}_{0}\right\rangle^{\xi} N_{\text {pred }}=C
$$

where FP is calculated using the stabilized stress-strain hysteresis loop.

\section{Results and discussion}

\subsection{Cyclic deformation under stress-controlled uniaxial loading}

Figure 2 shows the evolution of the stress-strain hysteresis loops obtained from specimen 31BUN09 subjected to fully reversed axial force. The material is practically under a fully reversed stress cycling with $\Delta \sigma / 2=160 \mathrm{MPa}$. Ratcheting deformation occurs in the negative strain direction. It is also observed that the strain amplitude becomes smaller as the number of loading cycles increase, indicating cyclic hardening in the material. The shape of the stress-strain hysteresis loops are asymmetric during the first few loading cycles. Such a macroscopic deformation behavior is a manifestation of the twinning and detwinning mechanisms that take place during compression and tension loading reversals, respectively. As the number of loading cycles increases, the stress-strain hysteresis loops gradually become more and more symmetrical, indicating a change of the dominant deformation mechanism from twinning and detwinning to dislocation slips. 


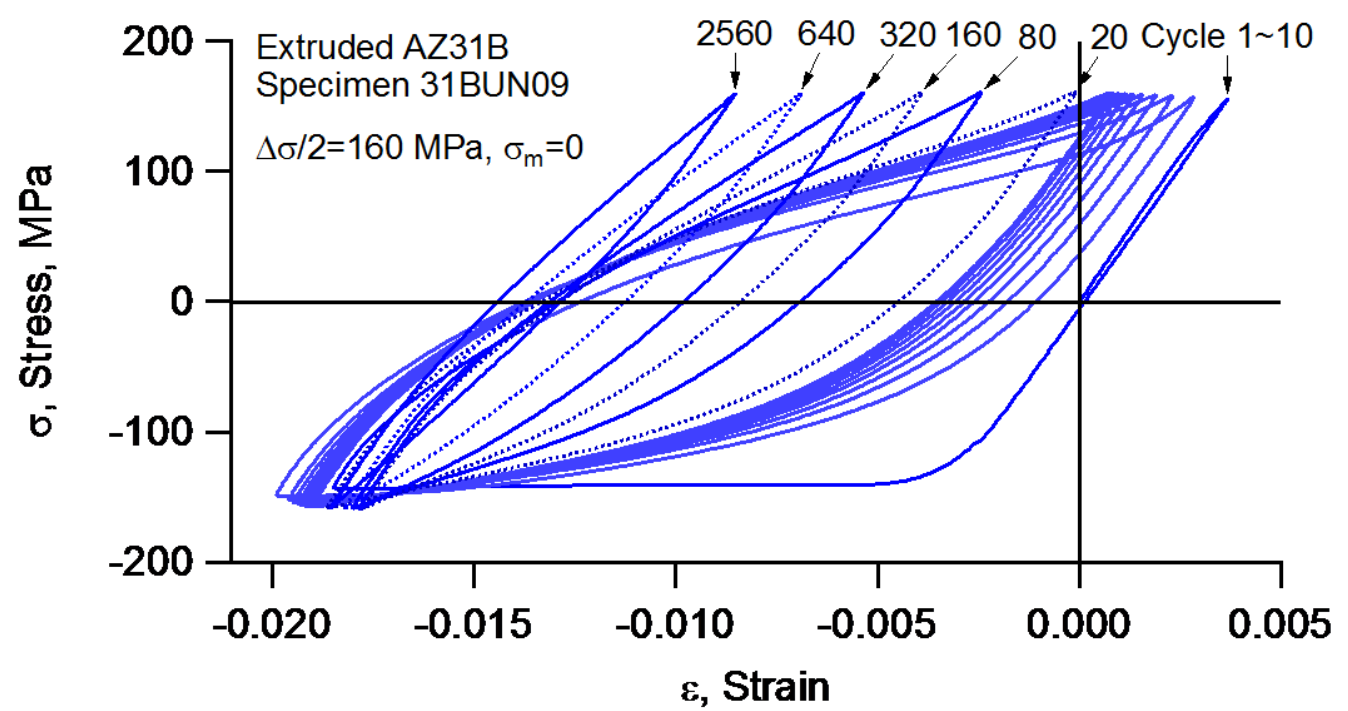

Figure 2. Stress-strain response of the fully reversed stress-controlled uniaxial experiment conducted on specimen 31BUN09.

Figure 3(a) shows the stress-strain hysteresis loops obtained from the two-step uniaxial loading experiment conducted on specimen 31BUN06. The loading history consists of zero-compression loading $\left(\Delta \sigma / 2=150 \mathrm{MPa}, \sigma_{\mathrm{m}}=-150 \mathrm{MPa}\right)$ followed by tension-compression loading $\left(\Delta \sigma / 2=225 \mathrm{MPa}, \sigma_{\mathrm{m}}=-75 \mathrm{MPa}\right)$ until fracture of the specimen into two parts. Twinning occurs during the first compressive loading reversal. The maximum stress in the subsequent cyclic loading is zero, which cannot activate bulk detwinning. As a result, plastic deformation is accommodated by dislocation slips. Minute strain ratcheting in the negative strain direction is observed together with cyclic hardening in the material. In the second loading step, the maximum stress is increased to $150 \mathrm{MPa}$. During the first loading cycles, asymmetric stress-strain hysteresis loops and minute cyclic hardening are observed. With increasing number of loading cycles, the stress-strain loops become more symmetrical and are accompanied by cyclic hardening.

(a)

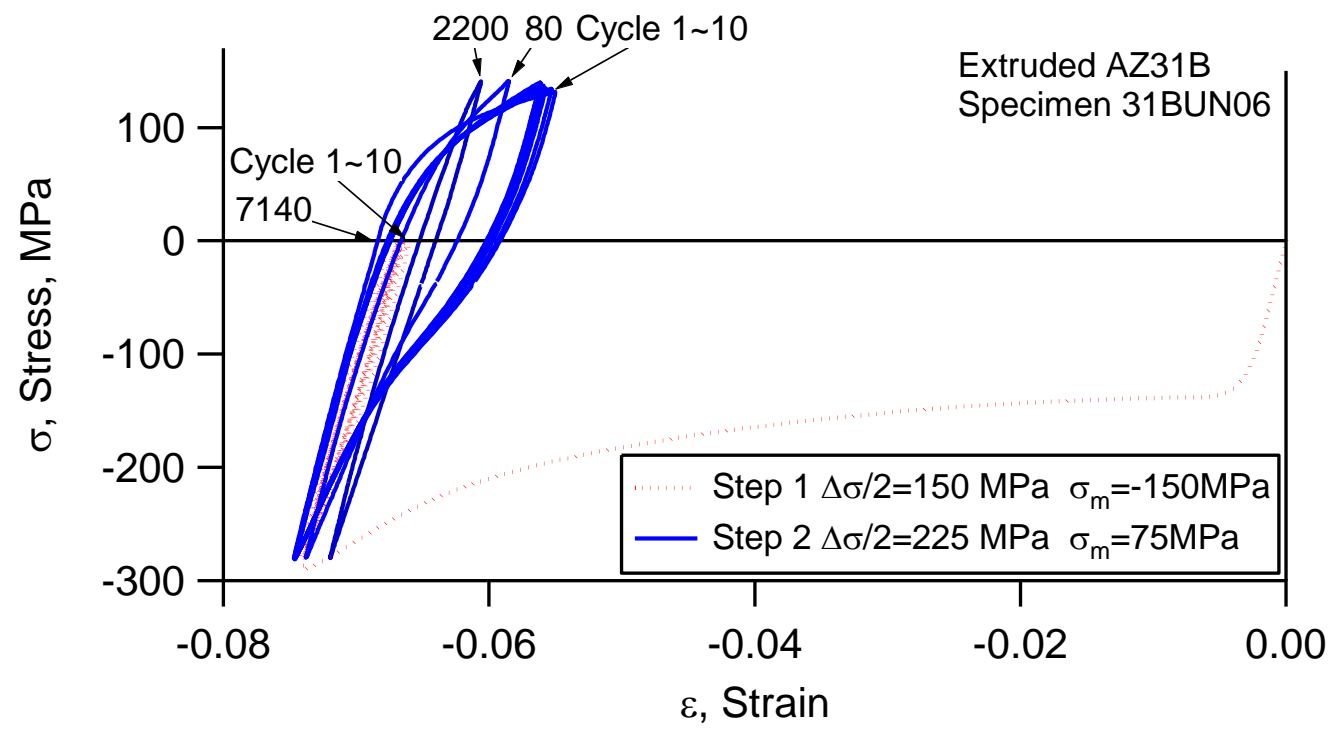

(b) 


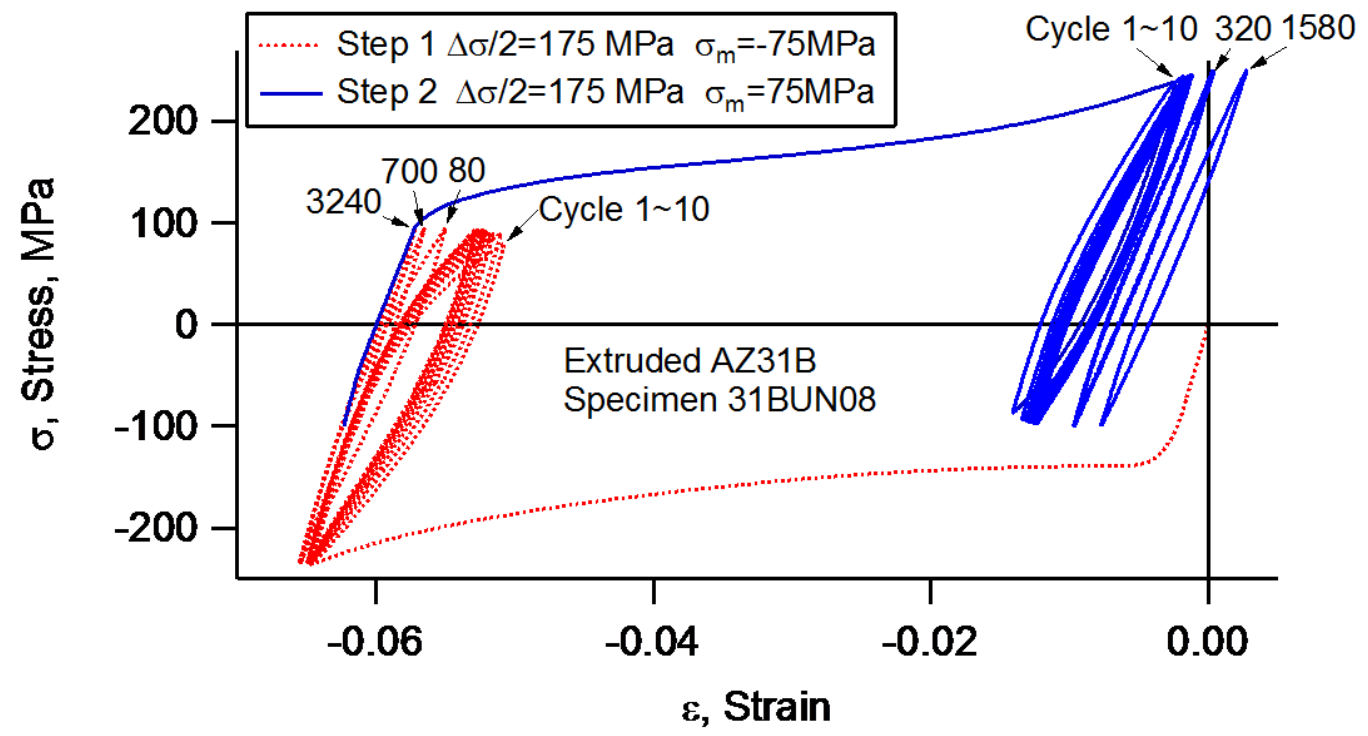

Figure 3. Stress-strain response of the two-step stress-controlled uniaxial experiment conducted on specimen 31BUN06 (a) and 31BUN08 (b).

To further illustrate the cyclic deformation behavior under two-step uniaxial loading, the stress-strain hysteresis loops obtained from specimen 31BUN08 are shown in Fig. 3(b). The loading sequence consisted of tension-compression loading with a compressive mean stress $\left(\Delta \sigma / 2=175 \mathrm{MPa}, \sigma_{\mathrm{m}}=-75 \mathrm{MPa}\right)$ followed by tension-compression loading having the same stress amplitude but with a tensile mean stress $\left(\Delta \sigma / 2=175 \mathrm{MPa}, \sigma_{\mathrm{m}}=75 \mathrm{MPa}\right)$. During the first step loading, twinning is the underlying deformation mechanism in the first compressive reversal followed by slip-dominated cyclic deformation involving ratcheting in the negative direction and cyclic hardening. In the second step loading, bulk detwinning is activated during the first tensile reversal. The minimum stress in the subsequent cyclic loading cannot activate twinning, and therefore dislocation slips operate as the dominant deformation mechanism. The evolution of the stress-strain hysteresis loops indicates the occurrence of cyclic hardening combined with ratcheting in the positive mean stress direction.

\subsection{Cyclic deformation under stress-controlled axial-torsion loading}

To illustrate the cyclic deformation behavior under stress-controlled axial-torsion loading, the experimental results obtained under $90^{\circ}$ out-of-phase loading are presented in Fig. 4. Ratcheting deformation is observed in both the axial and shear directions, with the axial strain ratcheting being more pronounced. The shape of the hysteresis loops are similar to the ones typically found in metals where dislocation slip-dominated deformation occurs (Jiang and Sehitoglu, 1994). This indicates that the applied loading conditions cannot active a twinning/detwinning process that is detectable at the macroscopic level. Plastic deformation is therefore accommodated by dislocation slips. 

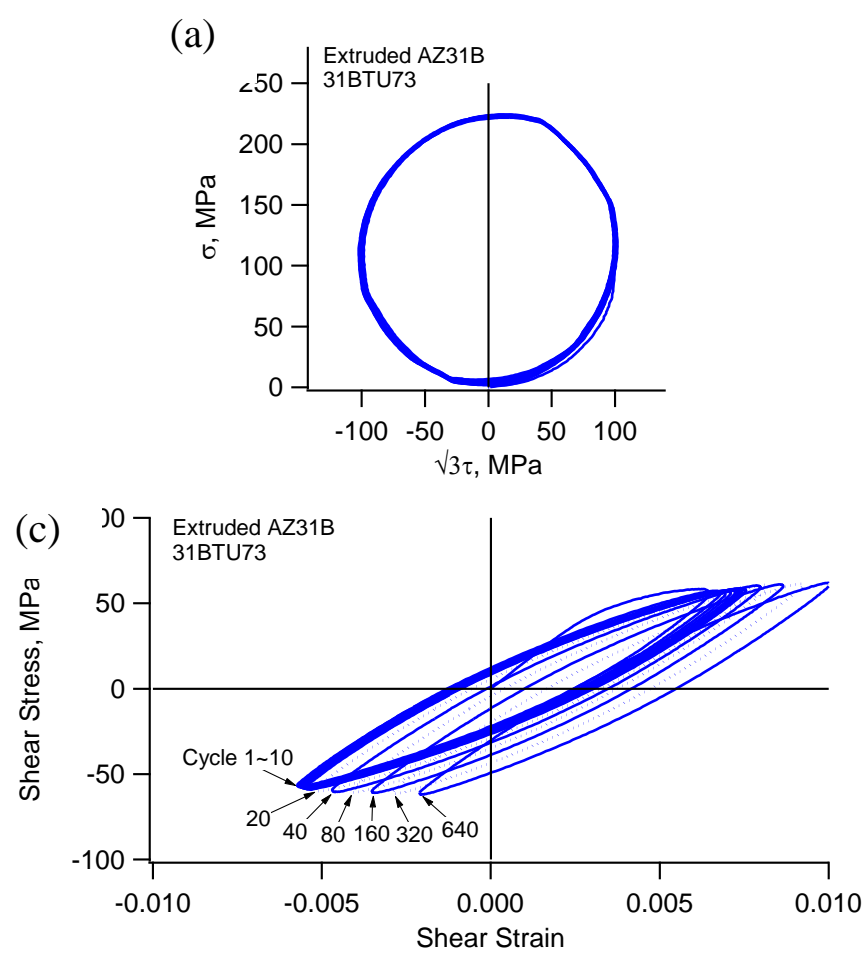

(b) 3007 Extruded AZ31B

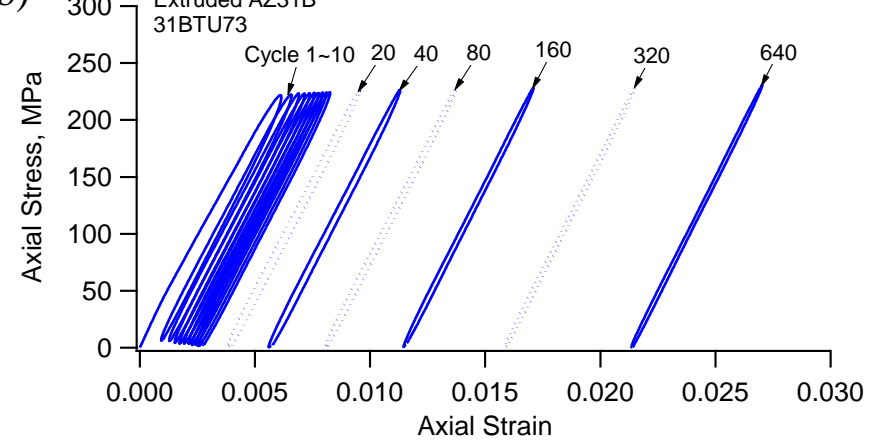

(d)

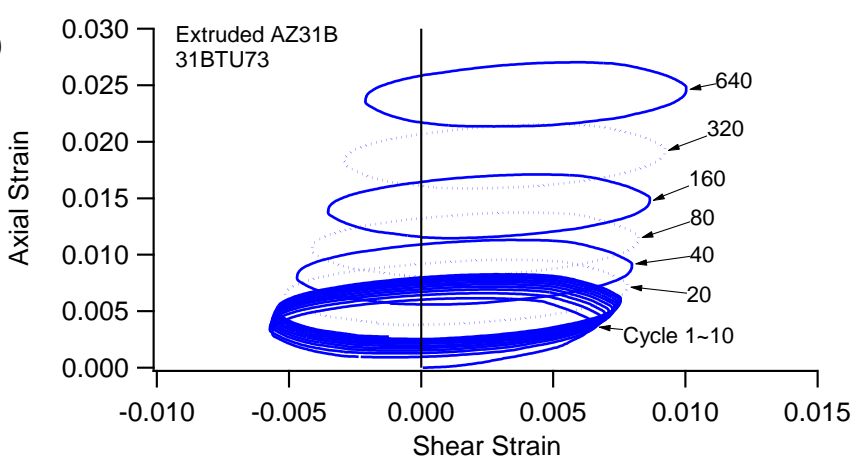

Figure 4. Nonproportional stress-controlled experiment conducted on specimen 31BTU73: (a) applied loading path; (b) axial stress-strain response; (c) shear stress-strain response; (d) axial strain-shear strain response.

\subsection{Cyclic deformation under strain-controlled axial-torsion loading}

The stress-strain hysteresis loops during strain-controlled two-step loading are illustrated in Fig. 5. The results refer to specimen 31BTU58 which was subjected to $90^{\circ}$ out-of-phase loading followed by fully reversed tension-compression. In the first step loading, cyclic hardening in both the axial and shear directions are observed. In addition, a small negative shear mean stress is developed which results in a slight asymmetry in the shear stress-shear strain hysteresis loops. The same cyclic deformation features under $90^{\circ}$ out-of-phase loading were observed in the experimental study of extruded AZ61 A Mg alloy carried out by Zhang et al. (2011). In the second step loading, the AZ31B Mg alloy exhibits typical asymmetric hysteresis loops observed under fully reversed tension-compression at a high strain amplitude.
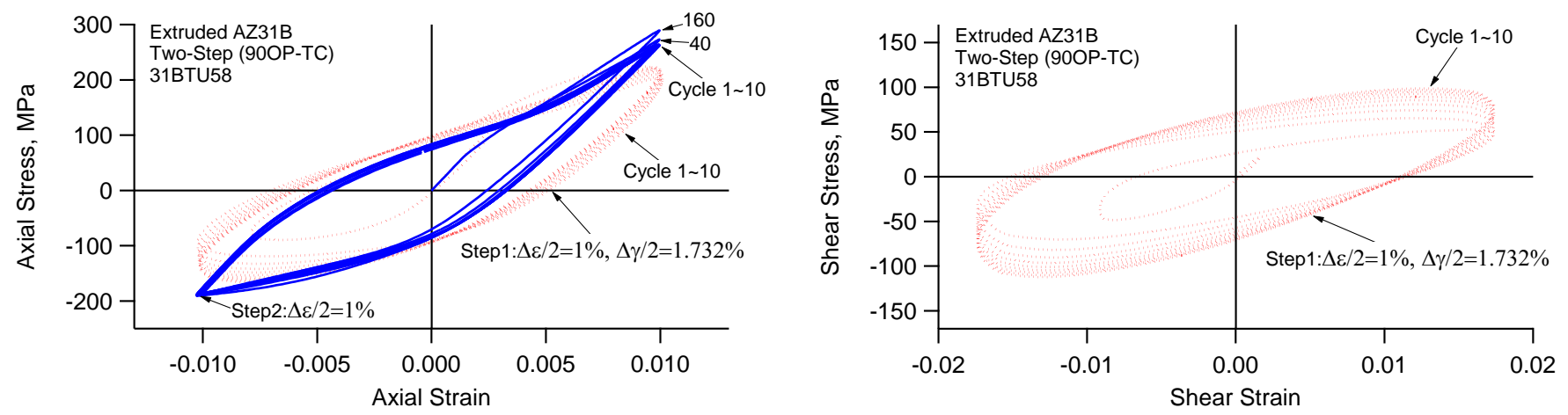
Figure 5. Stress-strain response of the two-step strain-controlled experiment conducted on specimen 31BTU58 (Step 1: $90^{\circ}$ out-of-phase axial-torsion loading; Step 2: fully reversed tension-compression).

\subsection{Fatigue life prediction}

The material constants used in the fatigue models were obtained in a previous publication (Castro and Jiang, 2016) using test data from fully reversed tension-compression and torsion experiments. The materials constants in the Jiang criterion are $b=0.38, \sigma_{0}=71 \mathrm{MPa}$, $m=0.9, \sigma_{\mathrm{f}}=338 \mathrm{MPa}$, and $D_{0}=400 \mathrm{MJ} / \mathrm{m}^{3}$. For the Fatemi-Socie criterion, $K=0.17$, $\sigma_{\mathrm{y}}=244 \mathrm{MPa}, \mathrm{FP}_{0}=0.00285, \xi=2.5$, and $C=0.0048$.

Fatigue life estimates were obtained by considering the change in fatigue damage during the loading history. For each experiment, detailed stress and strain data were available at predefined loading cycles. For the Jiang criterion, the fatigue damage accumulated at each of the predefined loading cycles was computed by numerically integrating Eq. (3). To calculate the cumulative fatigue damage over the loading history, the variation of the fatigue damage between two consecutive predefined loading cycles has to be specified. In the current work, such a variation was assumed to be linear due to the relative small interval between two consecutive predefined loading cycles. Fatigue failure was predicted when the cumulative fatigue damage on a material plane reached the threshold value, $D_{0}$. For the Fatemi-Socie criterion, fatigue life was predicted by means of a similar procedure involving Eqs. (7)-(9).

Figure 6 shows the variation of the fatigue damage per loading cycle, $\Delta D$, during the constant amplitude stress-controlled experiment conducted on specimen 31BUN09. For this loading case, cyclic hardening persisted during the whole fatigue life. As a result, the strain amplitude and the dissipated plastic strain energy per loading cycle varied significantly with increasing number of loading cycle. Such cyclic stress-strain response is reflected by a continuous decrease in the magnitude of the fatigue damage in the Jiang and Fatemi-Socie criteria. Due to the long-lived transient behavior in the material, a detailed cycle-by-cycle integration of the fatigue damage must be made in order to correctly determine the fatigue life. Indeed, for the Jiang criterion, the difference between the fatigue live predicted by Eq. (5) and the one based on the half-life stress-strain hysteresis loop (Eq. (6)) is approximately $60 \%$. For the Fatemi-Socie criterion, such a difference is $80 \%$.

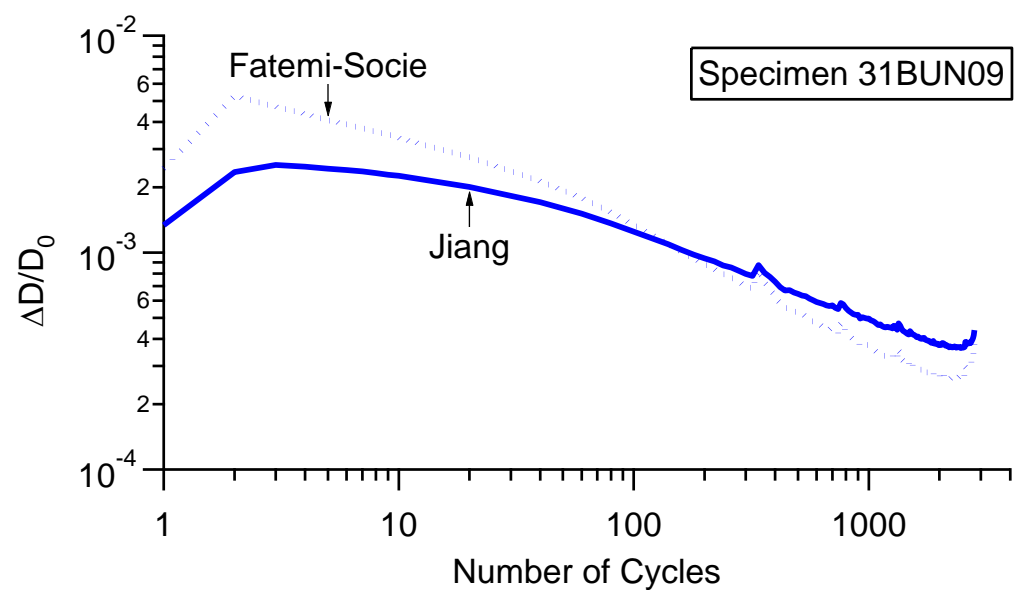


Figure 6. Variation of fatigue damage per loading cycle with loading history for the fully reversed stress-controlled experiment conducted on specimen 31BUN09.

Figure 7 shows a plot of the fatigue damage per loading cycle versus number of cycles for the two-step stress-controlled experiment conducted on specimen 31BUN08. The variation of the fatigue damage with the loading history reflects the stress-strain response of the material discussed in Section 4.1. The considerable amount of damage in the first loading cycle is related to the large strain in the first loading reversal as shown in Fig. 3(b). Subsequent cycling of the material results in persistent cyclic hardening which is accompanied by a decreasing fatigue damage per loading cycle. At the beginning of the second step loading, another peak of fatigue damage occurs due to the first tensile loading reversal. Further loading cycles again induce cyclic hardening in the material, which results in the continuous decrease of the fatigue damage per loading cycle until failure of the specimen.

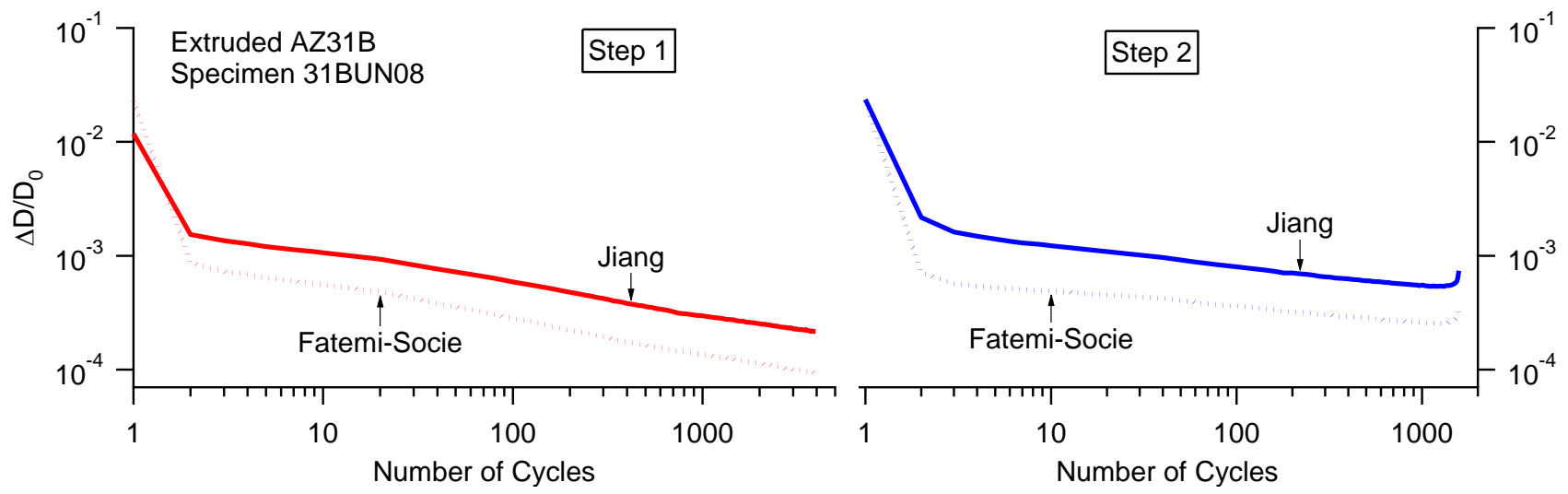

Figure 7. Variation of fatigue damage per loading cycle with loading history for the two-step stress-controlled experiment conducted on specimen 31BUN08.

Predicted versus observed fatigue lives are compared in Fig. 8 for the Jiang criterion, and in Fig. 9 for the Fatemi-Socie criterion. The reported fatigue lives for the step loading cases are the total number of cycles to failure. The thick solid line in the figures represents a perfect correlation and the dashed lines mark the factor-of-two boundaries. An arrow at a data point denotes a run-out experiment. In addition to the fatigue experiments conducted in the current work, strain-controlled experiments with strain ratios $R_{\varepsilon}=0$ and $R_{\varepsilon}=-\infty$ (taken from (Xiong et al., 2016)) were also included in the evaluation. 


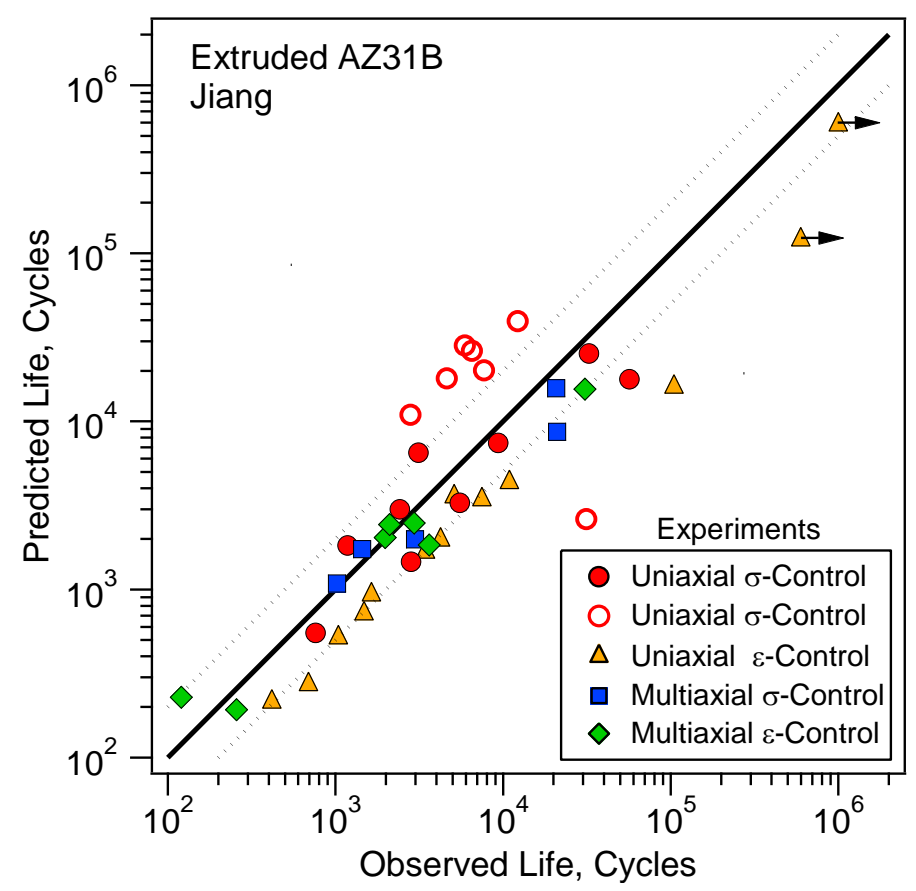

Figure 8. Observed fatigue lives versus predictions based on the Jiang criterion.

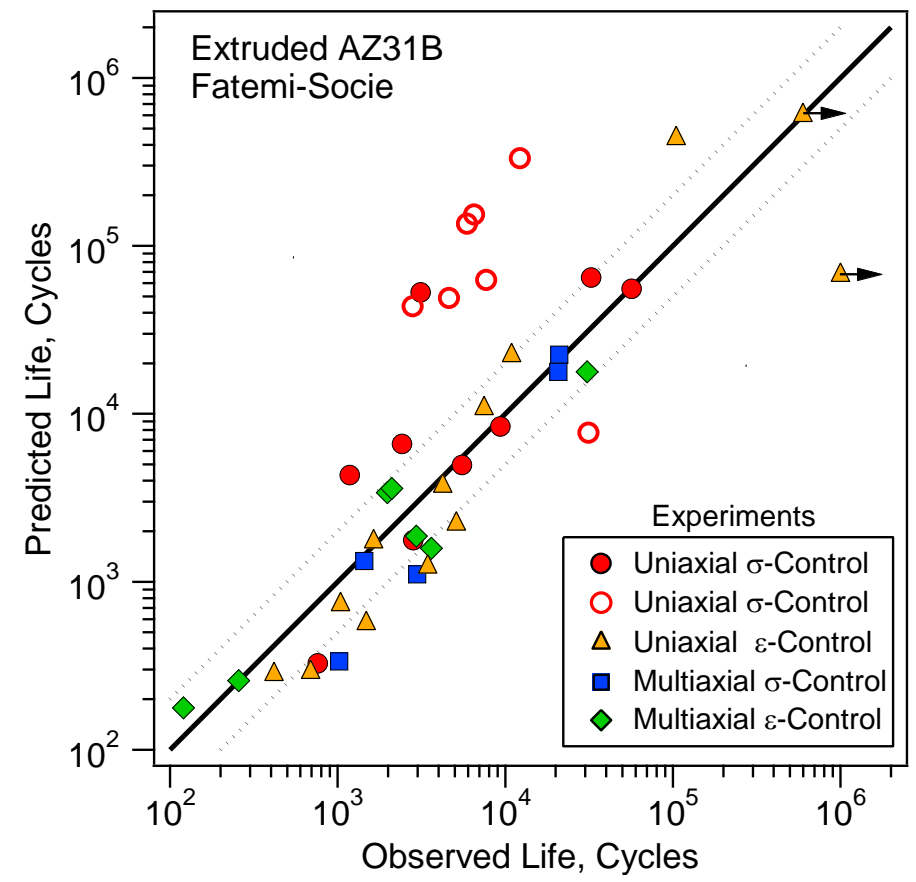

Figure 9. Observed fatigue lives versus predictions based on the Fatemi-Socie criterion.

Most predictions for the uniaxial strain-controlled experiments and the multiaxial strainand stress-controlled experiments are within the factor-of-two boundaries. This indicates that both fatigue criteria correlate well such experiments. In order to discuss the results for the uniaxial stress-controlled experiments, open red circles are used for specimens 31BUN21 through 31BUN27 and solid red circles for the other ones. The distinction is employed because the extruded AZ31B Mg alloy used to machine such specimens were obtained from different batches. Most of the solid red circles are within the factor-of-two boundaries for both fatigue criteria. However, the Fatemi-Socie criterion clearly overestimates the fatigue 
life of one of the experiments, namely, the fully reversed experiment with $R_{\sigma}=0$ conducted on specimen 31BUN04. Because such unsatisfactory prediction could be related to the wellknown scatter of fatigue lives, additional uniaxial stress-controlled experiments were carried out with $R_{\sigma}$ ranging from -1.5 to 0 . These experiments are the ones represented by the open red circles. Although less accurate predictions were observed for both fatigue criteria, the predictions by the Fatemi-Socie criterion were found to be quite non-conservative.

\subsection{Critical plane orientations}

A critical plane fatigue criterion may be regarded as successful if it can satisfactorily predict both the fatigue life and the critical plane orientation for different loading conditions. For the loading cases investigated, the cracking surface was observed to be perpendicular to the specimen surface. The cracking orientation can therefore be described using only the angle, $\theta$, formed between the specimen axis and the normal to the cracking surface and measured in the counterclockwise direction (Castro and Jiang, 2016). The fatigue crack was observed with a light optical microscope after the termination of an experiment, and cracking orientations were measured for macroscopic cracks having millimeter-scale length. The millimeter scale is adopted because the fatigue criteria under investigation are based on the macroscopic continuum mechanics concepts of stress and strain (Castro and Jiang, 2016; Jiang, 2000).
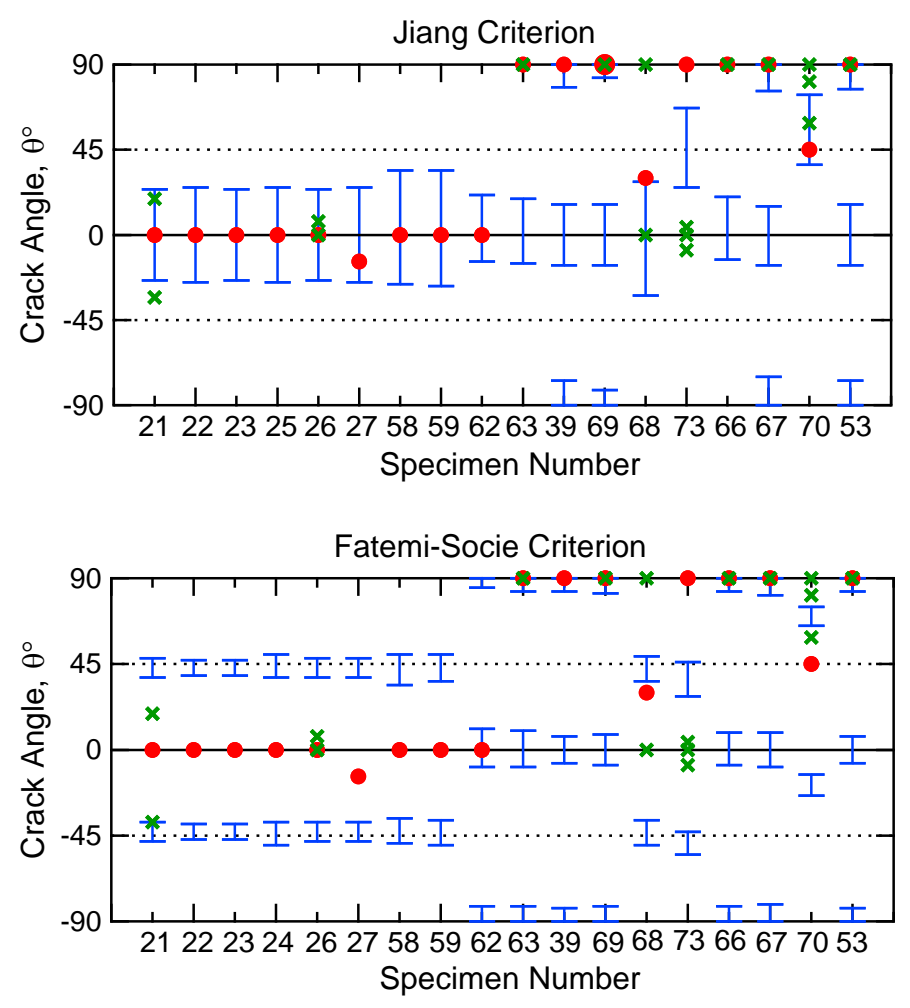

- Dominant Crack $\times$ Secondary Cracks - Prediction

Figure 10. Observed cracking orientations and predictions based on the Jiang criterion and the Fatemi-Socie criterion. 
The observed cracking orientations and the predictions based on the Jiang and Fatemi-Socie criteria are compared in Fig. 10. The red solid circle denotes the early cracking orientation of the dominant crack that grew into a large crack, and the ' $x$ ' symbol indicates the angle of a secondary crack. The vertical bars are the predicted ranges of the cracking angles. They were obtained by considering a range of $10 \%$ from the maximum fatigue damage predicted by a fatigue criterion. The choice of $10 \%$ range was introduced to consider the range of material planes that may experience similar fatigue damage according to a given fatigue criterion.

Among the 35 observed crack angles, the Fatemi-Socie criterion provided $37 \%$ correct predictions, whereas the cracking orientations of 23 specimens (66\%) were correctly predicted by the Jiang criterion. The accuracy of the cracking orientation predictions of both fatigue criteria are similar to the ones found in a previous study (Castro and Jiang, 2016) involving strain-controlled axial-torsion experiments on $\mathrm{AZ31} \mathrm{Mg}$ alloy under constant amplitude loading. In the particular case of the stress-controlled uniaxial experiments (specimens 31BUN21 through 31BUN27), the material exhibited tensile fatigue cracking $(\theta$ $\left.=0^{\circ}\right)$ in most of the experiments. Since the Fatemi-Socie criterion was developed for shear cracking fatigue failure, cracking orientation around the $\theta= \pm 45^{\circ}$ planes was incorrectly predicted. A characteristic of the Jiang criterion is that the material constant $b$ is used to consider different cracking behavior. The constant $b$ was identified to be 0.38 based on the observed cracking orientations of strain-controlled tension-compression and torsion experiments. With $b=0.38$ for AZ31B Mg alloy, the Jiang criterion can describe mixed cracking behavior. As a result, the Jiang criterion was capable of providing a good description of the cracking behavior under stress-controlled uniaxial experiments.

\section{Further discussion}

Many multiaxial fatigue models have been developed. A common practice in evaluating a fatigue model is to conduct experiments on twin-walled tubular specimens subjected to combined axial-torsion strain-controlled loading conditions. Good correlations of the experimental data are generally reported when conventional ductile metals are investigated. When a material is loaded in stress control, damage due to strain ratcheting and fatigue can occur. Limited work (Dallmeier et al., 2015; Liu et al., 2010; Varvani-Farahani, 2014) has been done on evaluating a fatigue model using stress-controlled cyclic experiments, especially under multiaxial loading conditions. For the case of $\mathrm{Mg}$ alloys, attempts [30] have been made to model the fatigue-ratcheting damage using stress-based parameters. Such an approach, however, may not properly describe situations involving significant twinning-detwinning activity. This is because the strain amplitude can vary significantly over a stress-controlled loading history due to cyclic hardening in the material (Xiong and Jiang, 2014). It is also worthwhile to note that a strain-based damage parameter that is successful in correlating strain-controlled fatigue experiments may have a difficulty in predicting the fatigue behavior of stress-controlled experiments. For example, while the authors have noted success with the Fatemi-Socie parameter in a previous publication (Castro and Jiang, 2016) and for most of the experiments presented in the current work, the 
use of Eq. (7) severely overestimates the fatigue life of a few of the uniaxial stress-controlled experiments. It is noted that the Fatemi-Socie parameter does not incorporate the damage caused by ratcheting strain and this may be one reason for such less desirable fatigue life predictions.

In continuum-based fatigue models, the variation of fatigue damage with time (or loading cycle) is related to the stress-strain response at a material point. When the transient cyclic behavior is not pronounced and a stabilized stress-strain response can be identified, the fatigue damage produced by the stable stress-strain hysteresis loop can provide a good estimate of the fatigue life. For situations involving complicated stress-strain response, the variation of the fatigue damage with the loading history should be considered when estimating fatigue life (Jiang and Kurath, 1997). With an incremental form, Jiang criterion can naturally track the variation of the fatigue damage along a general stress-strain history. In contrast, most fatigue criteria use stress/strain quantities such as strain amplitude and maximum stress that are based on the definition of a loading cycle or reversal. As a result, a cycle-counting method is needed to assess fatigue damage under variable amplitude loading conditions. The rainflow method is a well-established technique to identify a cycle or reversal of uniaxial strain-controlled histories. However, difficulties may arise for stresscontrolled histories because the stress-strain hysteresis loops do not close. An additional difficult is the treatment of nonproportional multiaxial loading because the stress and strain quantities on a material plane may not form consistent stress-strain hysteresis loops for normal and shear components. However, when the stress-strain data is stored in a cycle-bycycle basis, such difficulties may be circumvented by calculating the damage parameter associated with each loading cycle. This procedure was adopted in the current work when applying the Fatemi-Socie parameter to the fatigue experiments.

Damages due to fatigue and strain ratcheting are developed in a material subjected to asymmetrical stress-controlled loading. As yet it is difficult to quantify the relative importance of these two types of damage and modeling approaches have treated them as independent and competitive mechanisms (Kapoor, 1994) or by combining them into a single damage parameter (Jiang and Sehitoglu, 1999; Varvani-Farahani, 2014). The Jiang criterion incorporates both the fatigue damage and ratcheting damage, therefore the need of separate damage models is eliminated. The current experimental evaluation using AZ31B Mg alloy and previous results for 1070 steel (Jiang, 2000) and pure polycrystalline copper (Zhang and Jiang, 2006) suggest that the Jiang criterion has a good capability in predicting fatigue life under stress-controlled conditions.

\section{Conclusions}

Two critical plane approaches were used for the prediction of the uniaxial and axial-torsion fatigue behavior of extruded AZ31B Mg alloy. Constant amplitude loading and step loading experiments under both stress- and strain-controlled conditions were investigated. In order to deal with the complicated cyclic deformation behavior of the material, the variation of fatigue damage with loading cycle was determined using the stress-strain hysteresis loops obtained from the experiments. The Jiang criterion provided 
fatigue life and cracking orientation predictions with acceptable accuracy. The Fatemi-Socie criterion also yielded reasonable results for most of the fatigue experiments, but did not correlate well some of the test data obtained under uniaxial stress-controlled loading.

\section{Acknowledgments}

Fábio Castro would like to thank the support provided by CAPES - Brazil (BEX 6715/141). Yanyao Jiang acknowledges support from the National Science Foundation (CMMI1462885).

\section{References}

Agnew, S.R., 2004. Wrought magnesium: a 21st century outlook. JOM. 56, 20-21.

Albinmousa, J., Jahed, H., Lambert, S., 2011. Cyclic behaviour of wrought magnesium alloy under multiaxial load. Int. J. Fatigue 33, 1127-1139.

Albinmousa, J., Jahed, H., 2014. Multiaxial effects on LCF behaviour and fatigue failure of AZ31B magnesium extrusion. Int. J. Fatigue 67, 103-116.

Begum, S., Chen, D.L., Xu, S., Luo, A.A., 2009. Effect of strain ratio and strain rate on low cyclic fatigue behavior of AZ31wrought magnesium alloy. Mater. Sci. Eng. A 517, 334-343.

Bentachfine, S., Pluvinage, G., Toth, L.S., Azari, Z., 1996. Biaxial low cycle fatigue under non-proportional loading of a magnesium-lithium alloy. Eng. Fract. Mech. 54, 513-522.

Bettles, C., Barnett, M. (Eds.) 2012. Advances in wrought magnesium alloys: Fundamentals of processing, properties and applications. Publisher: Woodhead Publishing.

Bettles, C., Gibson, M., 2005. Current wrought magnesium alloys: strengths and weaknesses. JOM 57, 46-49.

Castro, F.C., Jiang, Y., 2016. Fatigue life and early cracking predictions of extruded AZ31B magnesium alloy using critical plane approaches. Int. J. Fatigue 88, 236-246.

Chen, L., Wang, C., Wu, W., Liu, Z., Stoica, G., Wu, L., 2007. Low-cycle fatigue behavior of an as-extruded AM50 magnesium alloy. Metall. Mater. Trans. A 38, 2235-2241.

Chen, G., Lu, L.T., Cui, Y., Xing, R.S., Gao, H., Chen, X., 2015. Ratcheting and low-cycle fatigue characterizations of extruded AZ31B $\mathrm{Mg}$ alloy with and without corrosive environment. Int. J. Fatigue 80, 364-371.

Dallmeier, J., Huber, O., Saage, H., Eigenfeld, K., 2015. Uniaxial cyclic deformation and fatigue behavior of AM50 magnesium alloy sheet metals under symmetric and asymmetric loadings. Mater. Des. 70, 10-30.

Fatemi, A., Socie, D.F., 1988. A critical plane approach to multiaxial fatigue damage including out-of-phase loading. Fatigue Fract. Eng. Mater. Struct. 11, 149-165.

Fatemi, A., Shamsaei, N., 2011. Multiaxial fatigue: An overview and some approximation models for life estimation. Int. J. Fatigue 33, 948-958.

Gaines, L., Cuenca, R., Stodolsky, F., Wu, S., 1996. Potential automotive uses of wrought magnesium alloys, Automotive Technology Development Conference, Detroit, Michigan.

Gao, Z., Zhao, T., Wang, X., Jiang, Y., 2009. Multiaxial fatigue of 16MnR steel. ASME J. Press. Vess. Technol. 131, 021403-1-021403-9. 
Hasegawa, S., Tsuchida, Y., Yano, H., Matsui, M., 2007. Evaluation of low cycle fatigue life in AZ31 magnesium alloy. Int. J. Fatigue 29, 1839-1845.

Jahed, H., Varvani-Farahani, A., 2006. Upper and lower fatigue life limits model using energy-based fatigue properties. Int. J. Fatigue 28, 467-473.

Jiang, Y., Sehitoglu, H., 1992. Fatigue and stress analysis of rolling contact. Report no. 161, UILU-ENG 92-3602. College of Engineering, University of Illinois at Urbana-Champaign.

Jiang, Y., Sehitoglu, H., 1994. Cyclic ratchetting of 1070 steel under multiaxial stress states. Int. J. Plasticity 10(5), 579-608.

Jiang, Y., Kurath, P., 1997. An investigation of cyclic transient behavior and implications on fatigue life estimates. ASME J. Eng. Mater. Technol. 119, 161-170.

Jiang, Y., Sehitoglu, H., 1999. A model for rolling contact failure. Wear 224, 38-49.

Jiang, Y., 2000. A fatigue criterion for general multiaxial loading. Fatigue Fract. Eng. Mater. Struct. 20, 19-32.

Jiang, Y., Hertel, O., Vormwald, M., 2007. An experimental evaluation of three critical plane multiaxial fatigue criteria. Int. J. Fatigue 29, 1490-1502.

Jordon, J.B., Brown, H.R., Haitham, E.H., Kistler, H.M., Lett, R.L., Baird, J.C., Luo, A.A., 2013. Investigation of fatigue anisotropy in an extruded magnesium alloy. Int. J. Fatigue 51, 8-14.

Kalnaus, S., Jiang, Y., 2008. Fatigue of AL6XN stainless steel. ASME J. Eng. Mater. Technol. 130, 031013-1-031013-12.

Kang, G., Yu, C., Liu, Y., Quan, G., 2014. Uniaxial ratchetting of extruded AZ31 magnesium alloy: Effect of mean stress. Mater. Sci. Eng. A 607, 318-327.

Kapoor, A., 1994. A re-evaluation of the life to rupture of ductile metals by cyclic plastic strain. Fatigue Fract. Eng. Mater. Struct. 17(2), 201-219.

Kim, K.S., Park, J.C., Lee, J.W., 1999. Multiaxial fatigue under variable amplitude loads. ASME J. Eng. Mater. Technol. 121, 286-293.

Kim, K.S., Lee, B.L., Park, J.C., 2000. Biaxial fatigue of stainless steel 304 under irregular loading. ASTM STP 1389, Halford, G.R., Gallagher, J.P. (Eds.), pp. 79-93.

Li, Q., Yu, Q., Zhang, J., Jiang, Y., 2010. Effect of strain amplitude on tension-compression fatigue behavior of extruded Mg6Al1ZnA magnesium alloy. Scripta Mater. 62, 778-781.

Li, H., Kang, G., Liu, Y., Jiang, H., 2016. Non-proportionally multiaxial cyclic deformation of AZ31 magnesium alloy: Experimental observations. Mater. Sci. Eng. A 671, 70-81.

Lin, Y.C., Liu, Z.H., Chen, X.M., Chen, J., 2013a. Uniaxial ratcheting and fatigue failure behaviors of hot-rolled AZ31B magnesium alloy under asymmetrical cyclic stress-controlled loadings. Mater. Sci. Eng. A 573, 234-244.

Lin, Y.C., Chen, X.M., Liu, Z.H., Chen, J., 2013b. Investigation of uniaxial low-cycle fatigue failure behavior of hot-rolled AZ91 magnesium alloy. Int. J. Fatigue 48, 122-132.

Lin, Y.C., Liu, Z.H., Chen, X.M., Chen, J., 2013c. Stress-based fatigue life prediction models for AZ31B magnesium alloy under single-step and multi-step asymmetric stress-controlled cyclic loadings. Comput. Mater. Sci. 73, 128-138.

Liu, Y., Kang, G., Gao, Q., 2010. A multiaxial stress-based fatigue failure model considering ratchetting-fatigue interaction. Int. J. Fatigue 32, 678-684. 
Lv, F., Yang, F., Duan, Q.Q., Luo, T.J., Yang, Y.S., Li, S.X., Zhang, Z.F., 2009. Tensile and low-cycle fatigue properties of $\mathrm{Mg}-2.8 \% \mathrm{Al}-1.1 \% \mathrm{Zn}-0.4 \% \mathrm{Mn}$ alloy along the transverse and rolling directions. Scripta Mater. 61, 887-890.

Lv, F., Yang, F., Duan, Q.Q., Yang, Y.S., Wu, S.D., Li, S.X., Zhang, Z.F., 2011. Fatigue properties of rolled magnesium alloy (AZ31) sheet: Influence of specimen orientation. Int. J Fatigue 33, 672-682.

Miner, M.A., 1945. Cumulative damage in fatigue. J. Appl. Mech. 67, 159-164.

Palmgren, A., 1924. Die Lebensdauer von Kugellagern. Verfahrenstechnik, Berlin 68, 339341.

Park, S.H., Hong, S.G., Bang, W., Lee, C.S., 2010. Effect of anisotropy on the low-cycle fatigue behavior of rolled AZ31 magnesium alloy. Mater. Sci. Eng. A. 527, 417-323.

Pollock, T.M., 2010. Weight loss with magnesium alloys. Science 328, 986-987.

Rowe, J., 2012. Advanced materials in automotive engineering. Cambridge: Woodhead Publishing Limited.

Sajuri, Z.B., Miyashita, Y., Hosokai, Y., Mutoh, Y., 2008. Effects of Mn content and texture on fatigue properties of as-cast and extruded AZ61 magnesium alloys. Int. J. Mech. Sci. 48, 198-209.

Socie, D., Bannantine, J., 1988. Bulk deformation fatigue damage models. Mater. Sci. Eng. A 103, 3-13.

Socie, D.F., 1993. Critical plane approaches for multiaxial fatigue damage assessment. In: McDowell, D.L., Ellis, R. (Eds.), Advances in multiaxial fatigue, ASTM STP 1191, Philadelphia, pp. 7-36.

Varvani-Farahani, A., 2014. Fatigue-ratcheting damage assessment of steel samples under asymmetric multiaxial stress cycles. Theor. Appl. Fract. Mech. 73, 152-160.

Wang, F., Dong, J., Feng, M., Sun, J., Ding, W., Jiang, Y., 2014. A study of fatigue damage development in extruded Mg-Gd-Y magnesium alloy. Mater. Sci. Eng. A 589, 209-216.

Wen, B., Wang, F., Jin, L., Dong, J., 2016. Fatigue damage development in extruded Mg3Al-Zn magnesium alloy. Mater. Sci. Eng. A 667, 171-178.

Wu, L., Agnew, S.R., Ren, Y., Brown, D.W., Clausen, B., Stoica, G.M., Wenk, H.R., Liaw, P.K., 2010. The effects of texture and extension twinning on the low-cycle fatigue behavior of a rolled magnesium alloy, AZ31B. Mater. Sci. Eng. A 527, 7057-7067.

Wu, Y., Zhu, R., Cai, X., Liu, L., 2016. Fatigue behavior of variable-plane-rolled AZ31 magnesium alloy. Mater. Sci. Eng. A 650, 273-280.

Xiong, Y., Yu, Q., Jiang, Y., 2012. Multiaxial fatigue of extruded AZ31B magnesium alloy. Mater. Sci. Eng. A 546, 119-128.

Xiong, Y., Jiang, Y., 2014. Fatigue of ZK60 magnesium alloy under uniaxial loading. Int. J. Fatigue 64, 74-83.

Xiong, Y., Yu, Q., Jiang, Y., 2014. An experimental study of cyclic plastic deformation of extruded ZK60 magnesium alloy under uniaxial loading at room temperature. Int. J. Plasticity 53, 107-124.

Xiong, Y., Yu, Q., Jiang, Y., 2016. Cyclic deformation and fatigue of extruded AZ31B magnesium alloy under different strain ratios. Mater. Sci. Eng. A 649, 93-103.

Yu, Q., Zhang, J., Jiang, Y., 2011a. Fatigue damage development in pure polycrystalline magnesium under cyclic tension-compression loading. Mater. Sci. Eng. A 528, 7816-7826. 
Yu, Q., Zhang, J., Jiang, Y., Li, Q., 2011b. Multiaxial fatigue of extruded AZ61A magnesium alloy. Int. J. Fatigue 33, 437-447.

Yu Q, Zhang J, Jiang Y, Li Q. Effect of strain ratio on cyclic deformation and fatigue of extruded AZ61A magnesium alloy. Int J Fatigue 2012;44:225-33.

Zhang J, Jiang Y. Fatigue of polycrystalline copper with different grain sizes and texture. Int J Plasticity 2006;22:536-56.

Zhang J, Yu Q, Jiang Y, Li Q. An experimental study of cyclic deformation of extruded AZ61A magnesium alloy. Int J Plasticity 2011;27:768-87.

Zhang XP, Castagne S, Luo XF, Gu CF. Effects of extrusion ratio on the ratcheting behavior of extruded AZ31B magnesium alloy under asymmetrical uniaxial cyclic loading. Mater Sci Eng A 2011;528:838-45.

Zhao T, Jiang Y. Fatigue of 7075-T651 aluminum alloy. Int J Fatigue 2008;30:834-49. 